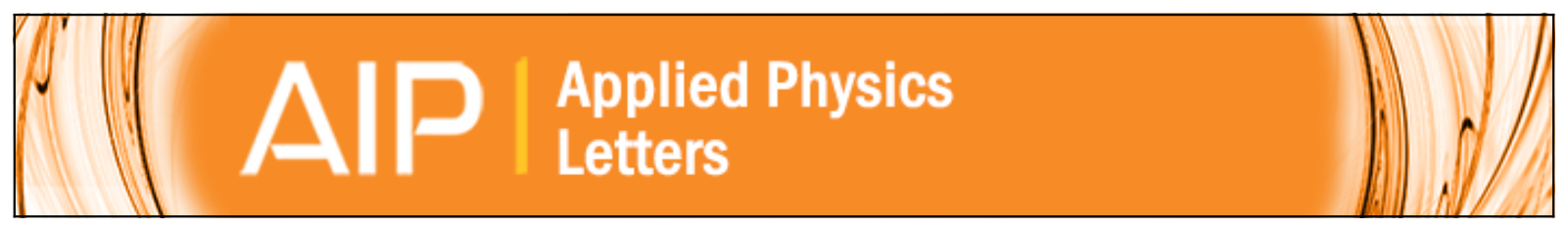

Enhanced light output of GaN-based light-emitting diodes with $\mathrm{ZnO}$ nanorod arrays

Sung Jin An, Jee Hae Chae, Gyu-Chul Yi, and Gil H. Park

Citation: Applied Physics Letters 92, 121108 (2008); doi: 10.1063/1.2903153

View online: http://dx.doi.org/10.1063/1.2903153

View Table of Contents: http://scitation.aip.org/content/aip/journal/apl/92/12?ver=pdfcov

Published by the AIP Publishing

Articles you may be interested in

Enhanced light output power of GaN-based light-emitting diodes by nano-rough indium tin oxide film using $\mathrm{ZnO}$ nanoparticles

J. Appl. Phys. 109, 093116 (2011); 10.1063/1.3575174

Influence of the alignment of $\mathrm{ZnO}$ nanorod arrays on light extraction enhancement of GaN-based light-emitting diodes

J. Appl. Phys. 109, 083110 (2011); 10.1063/1.3574441

Light enhancement of Al nanoclusters embedded in Al-doped $\mathrm{ZnO}$ films of GaN-based light-emitting diodes J. Vac. Sci. Technol. B 27, 1901 (2009); 10.1116/1.3167370

Enhanced light extraction efficiency of GaN-based light-emitting diodes with $\mathrm{ZnO}$ nanorod arrays grown using aqueous solution

Appl. Phys. Lett. 94, 071118 (2009); 10.1063/1.3077606

Enhanced efficiency of GaN-based light-emitting diodes with periodic textured Ga-doped ZnO transparent contact layer

Appl. Phys. Lett. 90, 263511 (2007); 10.1063/1.2753110

Want to publish your paper in the \#1 MOST CITED journal in applied physics?

With Applied Physics Letters, you can.

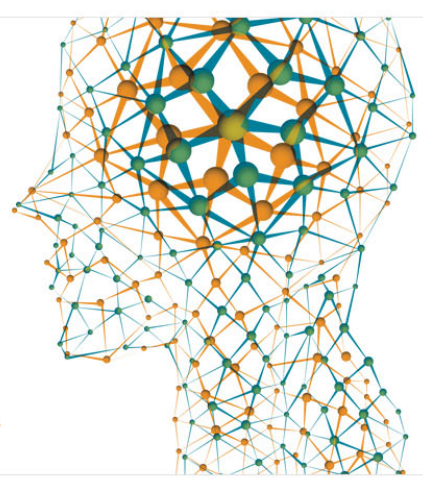




\title{
Enhanced light output of GaN-based light-emitting diodes with ZnO nanorod arrays
}

\author{
Sung Jin An, ${ }^{1}$ Jee Hae Chae, ${ }^{1}$ Gyu-Chul Yi, ${ }^{1, a)}$ and Gil H. Park ${ }^{2}$ \\ ${ }^{1}$ National CRI Center for Semiconductor Nanorods and Department of Materials Science and Engineering, \\ POSTECH, Pohang, Gyeongbuk 790-784, Republic of Korea \\ ${ }^{2}$ Central R\&D Institute, Samsung Electro-Mechanics, Su-Won, 443-743, Republic of Korea
}

(Received 20 November 2007; accepted 7 March 2008; published online 26 March 2008)

\begin{abstract}
We report enhanced light output of GaN-based light-emitting diodes (LEDs) with vertically aligned $\mathrm{ZnO}$ nanorod arrays. The $\mathrm{ZnO}$ nanorod arrays were prepared on the top layer of GaN LEDs using catalyst-free metalorganic vapor phase epitaxy. Compared to conventional GaN LEDs, light output of GaN LEDs with the $\mathrm{ZnO}$ nanorod arrays increased up to $50 \%$ and $100 \%$ at applied currents of 20 and $50 \mathrm{~mA}$, respectively. The source of the enhanced light output is also discussed. (C) 2008 American Institute of Physics. [DOI: 10.1063/1.2903153]
\end{abstract}

Considerable research has been recently devoted to the fabrication of high-brightness light-emitting diodes (LEDs) for general illumination. ${ }^{1}$ The internal quantum efficiency of GaN LEDs, which affects brightness, typically exceeds $70 \%$, much higher than the 10\%-25\% efficiency of conventional light sources such as light bulbs, incandescent electric lamps, and fluorescent lamps. ${ }^{2}$ Nevertheless, the total light-output efficiency of LEDs is reduced to a few percent by the low light-extraction efficiency (LEE) due to the total internal reflection of the light generated in the LED active layers. ${ }^{3}$ Accordingly, research has focused on methods of increasing the LEE of photons generated in the active layers, including LED dies, ${ }^{4}$ flip-chip LEDs, ${ }^{5}$ surface texturing, ${ }^{6,7}$ and twodimensional photonic crystals, ${ }^{8}$ as well as on overall LED efficiency. However, the methods require complex and expensive processes or may result in surface damage. ${ }^{9}$ Here, we report significantly improved light-output performance by growing vertically aligned semiconductor nanorod arrays on a top layer of GaN LEDs.

Since $\mathrm{ZnO}$ and $\mathrm{GaN}$ materials have similar refractive indices $(n=2.1-2.5)$, the Fresnel reflection between GaN and $\mathrm{ZnO}$ is significantly reduced; thus, $\mathrm{ZnO}$ nanorod arrays have been employed in semiconductors to enhance the lightoutput efficiency of InGaN/GaN multiple quantum well (MQW) LEDs. In addition, as the band gap energy of $\mathrm{ZnO}$ is higher than the energy of the light emitted from InGaN/GaN MQW layers and the lattice constant misfit of $1.9 \%$ is small, ${ }^{10}$ it is possible to heteroepitaxially grow high-quality $\mathrm{ZnO}$ nanorods on $\mathrm{GaN}$, thereby ensuring a clean interface between $\mathrm{ZnO}$ and $\mathrm{GaN}$ and preventing light absorption in $\mathrm{ZnO}$ nanorods. When the light generated from MQWs is incident to the nanorods, it is easily extracted through side facets and the tip of the nanorods. Thus, the growth of $\mathrm{ZnO}$ nanorod arrays on GaN LEDs will increase the LEE of the LEDs.

Figure 1(a) is a schematic of a GaN LED with vertically aligned $\mathrm{ZnO}$ nanorod arrays. InGaN/GaN MQW LEDs, showing a dominant electroluminescent (EL) peak at a wavelength of $460 \mathrm{~nm}$, were grown on the $c$-plane sapphire substrates by metalorganic vapor phase epitaxy (MOVPE) as

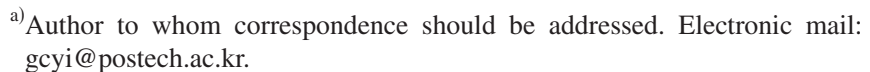

reported previously. ${ }^{11}$ Briefly, after the GaN LED substrates were cleaned with acetone and methanol in an ultrasonic bath, vertically well aligned $\mathrm{ZnO}$ nanorod arrays were heteroepitaxially grown on the top layer of the LEDs by catalyst-free MOVPE. Diethylzinc and oxygen, at flow rates of 0.5-9 SCCM (SCCM denotes cubic centimeter per minute at STP) and 20-100 SCCM, respectively, were employed as the reactant gases. ${ }^{12}$ The surface morphology of the grown $\mathrm{ZnO}$ nanorods was investigated using fieldemission gun-scanning electron microscopy. As shown in Fig. 1(b), the $\mathrm{ZnO}$ nanorods exhibited a uniform distribution in both diameter $(\sim 40 \mathrm{~nm})$ and length $(\sim 1 \mu \mathrm{m})$, with a density as high as $10^{10} / \mathrm{cm}^{2}$. The inset of Fig. 1 (b) shows the morphology of a $\mathrm{ZnO}$ nanorod on top of a $\mathrm{Ni} / \mathrm{Au}$ metal electrode. Note that the nanorod arrays on $\mathrm{Ni} / \mathrm{Au}$ are vertically well aligned, with diameters, lengths, and density similar to those of $\mathrm{ZnO}$ nanorods grown on the open areas of the LEDs.

(a)

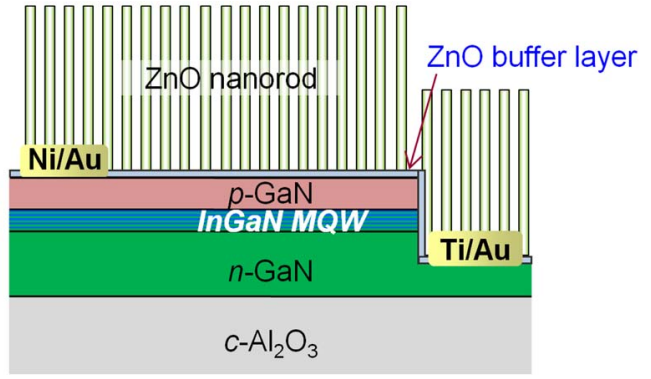

(b)

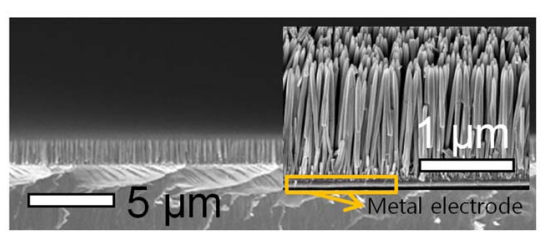

FIG. 1. (Color online) (a) Schematic of a GaN LED with vertical ZnO nanorod arrays. (b) FEG-SEM image of $\mathrm{ZnO}$ nanorod arrays grown on a GaN LED. ZnO nanorods are well aligned and are perpendicular to the GaN LED surface. The inset shows the morphology of a $\mathrm{ZnO}$ nanorod on top of a $\mathrm{Ni} / \mathrm{Au}$ metal electrode, which are vertically well aligned, and the diameter/length/density is similar to that of $\mathrm{ZnO}$ nanorods in the open areas of the LEDs. 
(a)

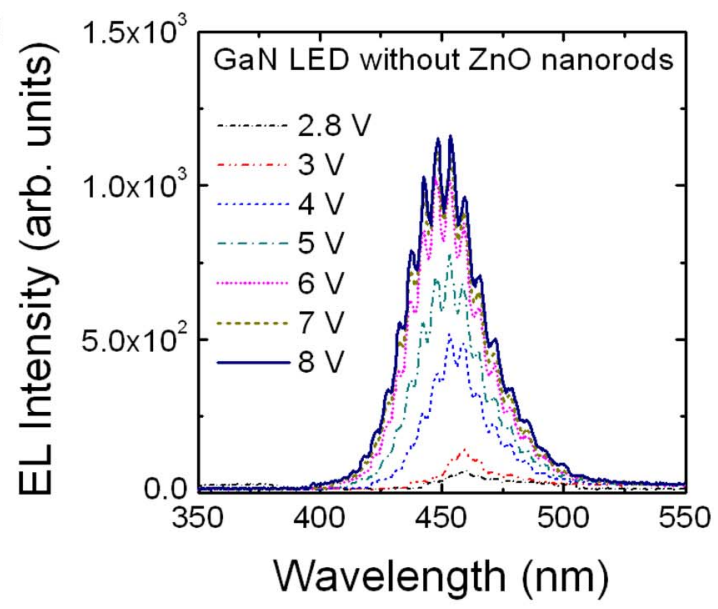

(b)

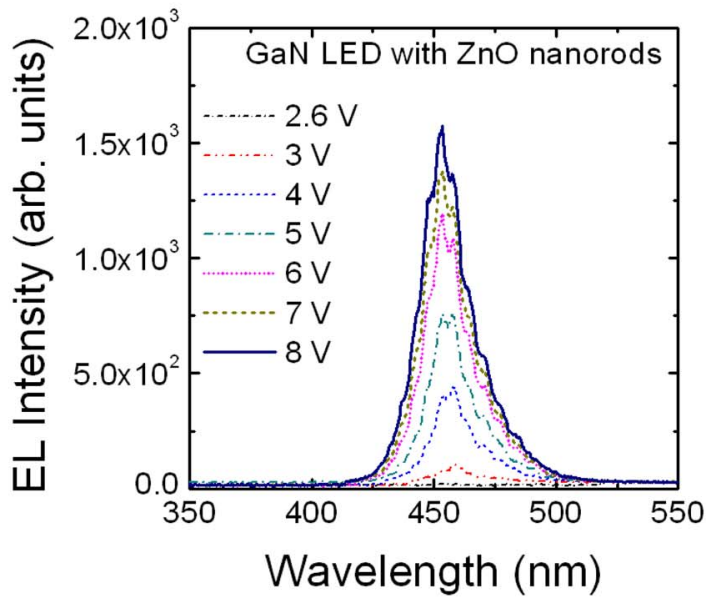

FIG. 2. (Color online) Room temperature EL spectra of GaN LEDs (a) without and (b) with $\mathrm{ZnO}$ nanorod arrays. The peak wavelength of $\mathrm{GaN}$ LEDs containing $\mathrm{ZnO}$ nanorod arrays shows a small, blueshift from $457 \mathrm{~nm}$ at $1 \mathrm{~mA}$ to $454 \mathrm{~nm}$ at $80 \mathrm{~mA}$, while the GaN LEDs without $\mathrm{ZnO}$ nanorods exhibit a significant blueshift from $459 \mathrm{~nm}$ at $1 \mathrm{~mA}$ to $450 \mathrm{~nm}$ at $80 \mathrm{~mA}$. In addition, the EL spectrum of GaN LED with $\mathrm{ZnO}$ nanorod arrays shows a smaller full width at half maximum value of the dominant peak than conventional GaN LEDs without exhibiting any interference effect.

EL and current-voltage $(I-V)$ curves for the LEDs were measured at various forward- and reverse-bias voltages at room temperature. The EL spectra were recorded using a monochromator and a photon-counting system equipped with a charge-coupled device, as detailed elsewhere. ${ }^{13}$ Briefly, when a direct-current bias voltage was applied to the LEDs from a source meter, light was emitted from the front of the diodes through the $\mathrm{ZnO}$ nanorod array, and the EL intensities were recorded at various current levels at room temperature. $\mathrm{ZnO}$ nanorod arrays on the LEDs exhibited a transmittance of over $90 \%$ in the visible region with a sharp, fundamental absorption edge at $380 \mathrm{~nm}$. To confirm the reliability of the fabrication process and the characteristics of the GaN LEDs, more than 30 LED devices were tested; they all exhibited similar optical and electrical characteristics.

The EL spectra of GaN LEDs, with and without $\mathrm{ZnO}$ nanorod arrays, as shown in Fig. 2, exhibited a dominant EL emission peak at $456 \mathrm{~nm}$ only. The absence of defect-related emission peaks strongly suggests that the growth of $\mathrm{ZnO}$ nanorods on GaN LEDs does not induce the formation of any radiative defects or damage on the GaN surface. With an increase in the applied current from 1 to $80 \mathrm{~mA}$, the peak wavelength of GaN LEDs containing $\mathrm{ZnO}$ nanorod arrays (a)

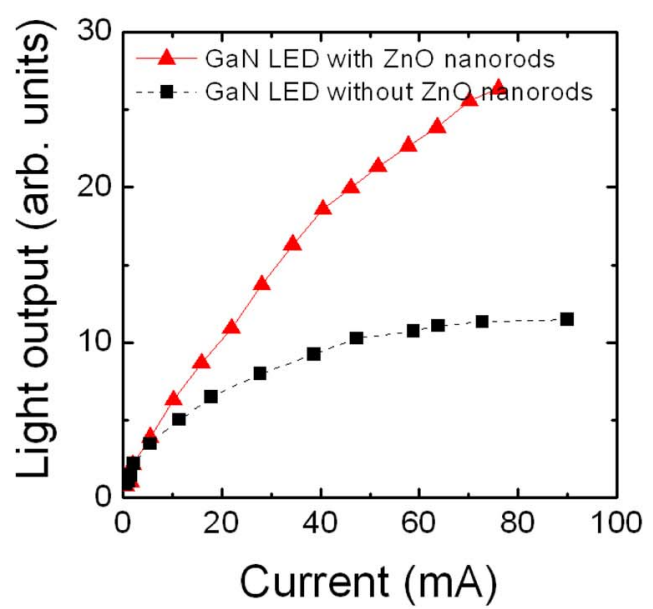

(b)

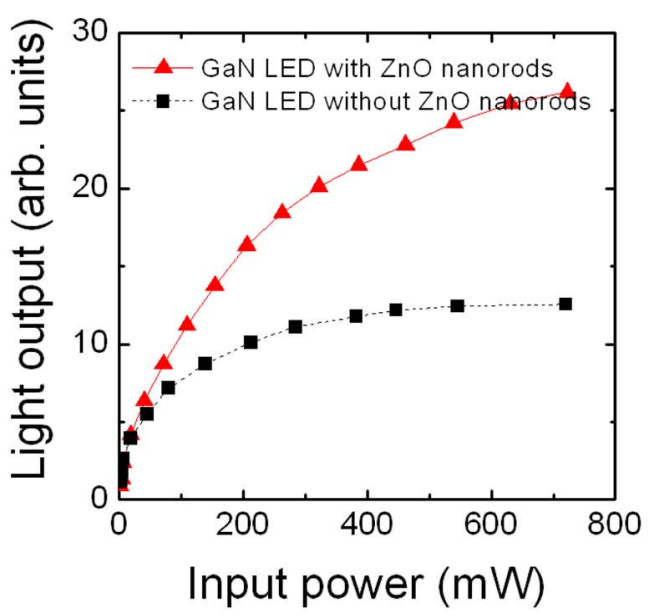

FIG. 3. (Color online) Light output power $(L)$ as a function of (a) current $(I)$ and (b) input power of GaN LEDs with and without $\mathrm{ZnO}$ nanorod arrays. The light output powers of the GaN LEDs with $\mathrm{ZnO}$ nanorods at currents of 20 and $50 \mathrm{~mA}$ were $50 \%$ and $100 \%$ higher, respectively, than those of the GaN LEDs without $\mathrm{ZnO}$ nanorods. Furthermore, the light output power of GaN LEDs without $\mathrm{ZnO}$ nanorods was almost saturated for currents above $60 \mathrm{~mA}$, while GaN LEDs with $\mathrm{ZnO}$ nanorods showed no saturation up to $80 \mathrm{~mA}$.

exhibited only a small blueshift from 457 to $454 \mathrm{~nm}$. In contrast, GaN LEDs without $\mathrm{ZnO}$ nanorods showed a significant blueshift from 459 to $450 \mathrm{~nm}$, presumably as a result of band filling ${ }^{14}$ and screening effects induced in the InGaN/GaN QW layers under a piezoelectric field. ${ }^{15,16}$ The smaller blueshift in the EL peak position of GaN LEDs with $\mathrm{ZnO}$ nanorods is evidence that the $\mathrm{InGaN} / \mathrm{GaN} \mathrm{QW}$ layer has smaller internal field. Thus, we contend that the electrical field of GaN LEDs can be changed by growing $\mathrm{ZnO}$ nanorods on $p-\mathrm{GaN}$, and that with the reduction in internal polarization, $\mathrm{GaN}$ LEDs with $\mathrm{ZnO}$ nanorods are very promising as high-efficiency LEDs. Furthermore, due to interference of the emitted light reflected by the sapphire/GaN and GaN/air interfaces and the smaller full width at half maximum value $(18 \mathrm{~nm})$ of the dominant EL peak compared to GaN LEDs without $\mathrm{ZnO}$ nanorods $(25 \mathrm{~nm})$, the $\mathrm{EL}$ spectrum of $\mathrm{GaN}$ LEDs with $\mathrm{ZnO}$ nanorod arrays exhibits greatly reduced multiple fringes. These results indicate that the $\mathrm{ZnO}$ nanorod arrays on GaN LEDs result in a decrease in the total internal reflection of the generated light in the active region of the LED. $^{17}$

To further investigate the EL characteristics of $\mathrm{GaN}$ LEDs with $\mathrm{ZnO}$ nanorods, light output power $(L)$ was mea- 


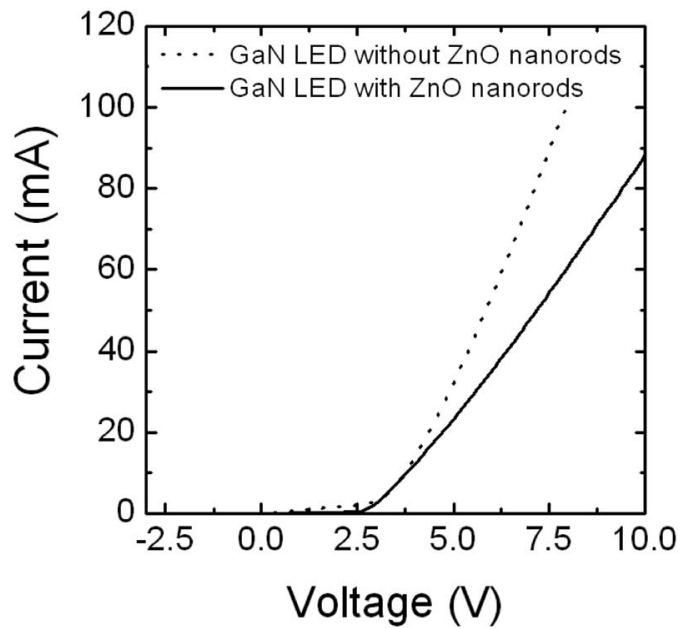

FIG. 4. I-V curves of LEDs with and without $\mathrm{ZnO}$ nanorods. Both $I-V$ curves of the LEDs with and without $\mathrm{ZnO}$ nanorods exhibited nonlinear and good rectifying behavior with a turn-on voltage of $2.8 \mathrm{~V}$ and a leakage current of $1 \times 10^{-5} \mathrm{~A}$ at $-5 \mathrm{~V}$. However, series resistance of the GaN LEDs increased from 50 to $83 \Omega$ after $\mathrm{ZnO}$ nanorod growth.

sured as a function of current $(I)$ and input power. Figure 3(a) shows $L-I$ curves of GaN LEDs with and without $\mathrm{ZnO}$ nanorods. Since the experimental data were obtained from the same devices before and after $\mathrm{ZnO}$ nanorod growth on LED chips, other factors affecting the EL characteristics can be ignored. The $L-I$ curves of both GaN LEDs, measured in front (top side through the $\mathrm{ZnO}$ nanorod arrays) of the devices, exhibited increased light output power with increasing applied current. As shown in Fig. 3(b), the light output power of the LEDs similarly increased with increased input power. In particular, the light output power of the GaN LED with $\mathrm{ZnO}$ nanorods exhibited a $50 \%$ increase at $20 \mathrm{~mA}$, and furthermore, was not saturated up to $80 \mathrm{~mA}$. The GaN LEDs without $\mathrm{ZnO}$ nanorods, however, exhibited an almost saturated light output power at currents above $60 \mathrm{~mA}$. The greatly increased efficiency of the LEDs with $\mathrm{ZnO}$ nanorods at high current is a result of better heat dissipation through the nanorods due to both the higher thermal conductivity $(1.47 \mathrm{~W} / \mathrm{cm} \mathrm{K})$ of $\mathrm{ZnO}$ compared to sapphire $(0.3 \mathrm{~W} / \mathrm{cm} \mathrm{K})$ and the high surface/volume ratio of nanorod arrays. This is also confirmed by the small EL peak shift of the LEDs with $\mathrm{ZnO}$ nanorods due to the reduced device heating. Accordingly, the results strongly suggest that the GaN LEDs with $\mathrm{ZnO}$ nanorods exhibit a higher thermal stability as well as the increased LEE.

Electrical characteristics of the GaN LEDs were also determined from the $I$ - $V$ curves. Figure 4 shows $I$ - $V$ curves for the GaN LEDs with (solid line) and without (dotted line) $\mathrm{ZnO}$ nanorods on a $p$-GaN layer of the LEDs. Although the $\mathrm{ZnO}$ nanorods were subsequently coated on the $p$-GaN layer, the $I-V$ curve of the LEDs with $\mathrm{ZnO}$ nanorods exhibited nonlinear and good rectifying behavior with a turn-on voltage of $2.8 \mathrm{~V}$ and a leakage current of $1 \times 10^{-5} \mathrm{~A}$ at $-5 \mathrm{~V}$.
From the $I$ - $V$ curves in Fig. 4, the series resistances of GaN LEDs with and without $\mathrm{ZnO}$ nanorods were estimated to be 83 and $50 \Omega$, respectively. The increase in series resistance of GaN LEDs with $\mathrm{ZnO}$ nanorods may originate from scattering at the $\mathrm{ZnO} / \mathrm{GaN}$ layer interface. Also note that the operating voltage of the GaN LEDs with $\mathrm{ZnO}$ nanorods is higher than that of the LEDs without $\mathrm{ZnO}$ nanorods.

In conclusion, catalyst-free MOVPE of vertically aligned $\mathrm{ZnO}$ nanorods on GaN LEDs significantly increased their light output power. GaN LEDs with $\mathrm{ZnO}$ nanorod arrays had 50\% enhanced light output power at an applied current of $20 \mathrm{~mA}$ compared to conventional GaN LED, which further increased to $100 \%$ at $50 \mathrm{~mA}$, resulting presumably from increased LEE. This simple growth process for $\mathrm{ZnO}$ nanorods, without changing the LED structure, should be invaluable for increasing the fabrication yield and reducing the production costs of higher-brightness LEDs.

This work was financially supported by the Korea Science and Engineering Foundation under the National Creative Research Initiative Project (Contract No. R16-2004004-01001-0) of the Ministry of Science and Technology, Korea.

${ }^{1}$ S. Nakamura and G. Fasol, The Blue Laser Diode (Springer, Berlin, 1997). ${ }^{2}$ E. F. Schubert and J. K. Kim, Science 308, 1274 (2005).

${ }^{3}$ I. Schnitzer, E. Yablonovitch, C. Caneau, T. J. Gmitter, and A. Scherer, Appl. Phys. Lett. 63, 2174 (1993); M. Boroditsky and E. Yablonovitch, Proc. SPIE 3002, 119 (1997).

${ }^{4}$ M. R. Krames, M. Ochiai-Holcomb, G. E. Höfler, C. Carter-Coman, E. I. Chen, I.-H. Tan, P. Grillot, N. F. Gardner, H. C. Chui, J.-W. Huang, S. A. Stockman, F. A. Kish, and M. G. Craford, Appl. Phys. Lett. 75, 2365 (1999).

${ }^{5}$ J. J. Wierer, D. A. Steigerwald, M. R. Krames, J. J. O'Shea, M. J. Ludowise, G. Christenson, Y.-C. Shen, C. Lowery, P. S. Martin, S. Subramanya, W. Götz, N. F. Gardner, R. S. Kern, and S. A. Stockman, Appl. Phys. Lett. 78, 3379 (2001).

${ }^{6}$ C. Huh, K.-S. Lee, E.-J. Kang, and S.-J. Park, J. Appl. Phys. 93, 9383 (2003).

${ }^{7}$ T. Fujii, Y. Gao, R. Sharma, E. L. Hu, S. P. DenBaars, and S. Nakamura, Appl. Phys. Lett. 84, 855 (2004).

${ }^{8}$ J. J. Wierer, M. R. Krames, J. E. Epler, N. F. Gardner, J. R. Wendt, M. M. Sigalas, S. R. J. Brueck, D. Li, and M. Shagam, Proc. SPIE 5739, 102 (2005).

${ }^{9}$ X. A. Cao, S. J. Pearton, A. P. Zhang, G. T. Dang, F. Ren, R. J. Shul, L. Zhang, R. Hickman, and J. M. Van Hove, Appl. Phys. Lett. 75, 2569 (1999).

${ }^{10}$ S. J. An, W. I. Park, G.-C. Yi, Y.-J. Kim, H.-B. Kang, and M. Kim, Appl. Phys. Lett. 84, 3612 (2004).

${ }^{11}$ S.-N. Lee, T. Sakong, W. Lee, H. Paek, M. Seon, I.-H. Lee, O. Nam, and Y. Park, J. Cryst. Growth 250, 256 (2003).

${ }^{12}$ W. I. Park, D. H. Kim, S.-W. Jung, and G.-C. Yi, Appl. Phys. Lett. 80, 4232 (2002).

${ }^{13}$ W. I. Park and G.-C. Yi, Adv. Mater. (Weinheim, Ger.) 16, 87 (2004).

${ }^{14}$ Y. Narukawa, Y. Kawakami, M. Funato, S. Fujita, and S. Nakamura, Appl. Phys. Lett. 70, 981 (1997).

${ }^{15}$ D. A. Meller, D. S. Chemla, T. C. Damen, A. C. Gross, W. Wiegmann, T. H. Wood, and C. A. Burrus, Phys. Rev. Lett. 53, 2173 (1984).

${ }^{16}$ D. A. B. Miller, D. S. Chemla, and S. Schmitt-Rink, Phys. Rev. B 33, 6976 (1986).

${ }^{17}$ J. K. Kim, T. Gessmann, E. F. Schubert, J.-Q. Xi, H. Luo, J. Cho, C. Sone, and Y. Park, Appl. Phys. Lett. 88, 013501 (2006). 